\title{
Angiotensin Converting Enzyme Expression Is Increased in Small Pulmonary Arteries of Rats with Hypoxia-induced Pulmonary Hypertension
}

\author{
Nicholas W. Morrell, Elena N. Atochina, ${ }^{*}$ Kenneth G. Morris, Sergei M. Danilov, ${ }^{\ddagger}$ and Kurt R. Stenmark \\ Lung Developmental Biology Laboratory, University of Colorado Health Sciences Center, Denver, Colorado 80262; *Institute for \\ Environmental Medicine, University of Pennsylvania, Philadelphia, Pennsylvania 19104; and ${ }^{\ddagger}$ INSERM Unit 367, 75005 Paris, France
}

\begin{abstract}
Previous studies suggest that while lung angiotensin converting enzyme (ACE) activity is reduced during chronic hypoxia, inhibitors of ACE attenuate hypoxic pulmonary hypertension. In an attempt to explain this paradox we investigated the possibility that whole lung ACE activity may not reflect local pulmonary vascular ACE expression. The experimental approach combined in vivo hemodynamic studies in control and chronically hypoxic rats, measurement of whole lung ACE activity, and evaluation of local pulmonary vascular ACE expression by in situ hybridization and immunohistochemistry. Total lung ACE activity was reduced to $50 \%$ of control activity by $5 \mathrm{~d}$ of hypoxia and remained low for the duration of the study. Immunohistochemistry showed a marked reduction of ACE staining in alveolar capillary endothelium. However, an increase in ACE staining was observed in the walls of small newly muscularized pulmonary arteries at the level of alveolar ducts and walls. In situ hybridization studies showed increased signal for ACE mRNA in the same vessels. Inhibition of ACE by captopril during chronic hypoxia attenuated pulmonary hypertension and markedly reduced distal muscularization of small pulmonary arteries. In addition, we demonstrated marked longitudinal variation in ACE expression along the normal pulmonary vasculature with the highest levels found in small muscular arteries associated with terminal and respiratory bronchioles. We conclude that local ACE expression is increased in the walls of small pulmonary arteries during the development of hypoxic pulmonary hypertension, despite a generalized reduction in alveolar capillary ACE expression, and we speculate that local arteriolar ACE may play a role in the vascular remodeling associated with pulmonary hypertension. (J. Clin. Invest. 1995. 96:1823-1833.) Key words: hypoxia • pulmonary vascular disease • gene expression • immunohistochemistry • endothelium
\end{abstract}

\section{Introduction}

Pulmonary hypertension, such as occurs in response to chronic hypoxia, is a consequence of profound structural alterations in

Address correspondence to Kurt R. Stenmark, M.D., Lung Developmental Biology Laboratory, Box B-131, University of Colorado Health Sciences Center, 4200 East 9th Avenue, Denver, CO 80262. Phone: 303-270-4499; FAX: 303-270-8353.

Received for publication 21 April 1995 and accepted in revised form 26 June 1995.

J. Clin. Invest.

(C) The American Society for Clinical Investigation, Inc.

$0021-9738 / 95 / 10 / 1823 / 11 \$ 2.00$

Volume 96, October 1995, 1823-1833 the pulmonary vasculature (1), including thickening of the media and adventitia of pulmonary arteries and extension of muscle into previously nonmuscularized pulmonary arteries (1). The process is known to involve medial smooth muscle cell hypertrophy and hyperplasia $(2,3)$, fibroblast proliferation $(2,4)$, and matrix protein synthesis (4-6). Increasing evidence suggesting that angiotensin converting enzyme (ACE) ${ }^{1}$ plays an important role in systemic vascular pathology (7-10) led us to question whether changes in ACE expression may participate in the structural remodeling associated with pulmonary hypertension. In the systemic circulation, angiotensin II (AII), formed by the action of ACE on angiotensin I, has been shown to be an important mediator of vascular smooth muscle cell growth $(11,12)$ and thus potentially could modulate some of the structural changes associated with pulmonary hypertension. However, substantive evidence of a role for ACE in pulmonary hypertension is lacking, since, although inhibitors of ACE attenuate the medial thickening and right ventricular hypertrophy (13-15), most workers report a decrease in whole lung ACE activity during the development of pulmonary hypertension induced by chronic hypoxia (16-19) or ingestion of monocrotaline (20). These disparate findings have led others to conclude that the beneficial effects of ACE inhibitors on pulmonary hypertension are either independent of inhibition of lung ACE or that downregulation of lung ACE may be a protective mechanism.

In an attempt to explain this apparent paradox and seek evidence for an involvement of ACE in the pathogenesis of pulmonary hypertension, we questioned whether ACE expression might be increased locally in the pulmonary vessels undergoing structural remodeling, despite a reduction in whole lung ACE. Thus we measured whole lung ACE activity in lungs from rats with pulmonary hypertension, induced by chronic hypoxia for up to $14 \mathrm{~d}$, and determined local pulmonary vascular ACE expression by immunohistochemistry and in situ hybridization. Our findings demonstrate that ACE expression is increased in the walls of small newly muscularized pulmonary arteries during chronic hypoxia, despite a generalized reduction in pulmonary ACE activity. In additional experiments we studied the effect of the ACE inhibitor, captopril, on the vascular remodeling which occurs during chronic hypoxia. Inhibition of ACE in chronically hypoxic rats caused a marked reduction in the distal muscularization of normally nonmuscular small pulmonary arteries. These results suggest that locally increased ACE expression plays a role in the structural remodeling of hypoxic pulmonary hypertension.

\footnotetext{
1. Abbreviations used in this paper: ACE, angiotensin converting enzyme; AII, angiotensin II; APAAP, alkaline phosphatase anti-alkaline phosphatase; TR, Texas red.
} 


\section{Methods}

Hemodynamic studies. For study of the expression of ACE in the normal and chronically hypoxic lung, 40 male Sprague-Dawley rats (weight $\sim 250$ grams) were divided into five groups of eight animals. One group served as a normoxic control and was maintained at Denver's altitude of 5,300 feet. Four experimental groups of eight animals were maintained for $3,5,7$, or $14 \mathrm{~d}$ at a simulated altitude of 17,000 feet (equivalent to an inspired oxygen concentration of $\sim 10 \%$ ) in a hypobaric hypoxic chamber to induce pulmonary hypertension. After the specified period of hypoxia, rats were anesthetized (intramuscular ketamine 75 $\mathrm{mg} / \mathrm{kg}$ and xylazine $6 \mathrm{mg} / \mathrm{kg}$ ), and a polyethylene catheter was inserted into the right carotid artery for measurement of mean systemic pressure and a polyvinyl catheter was inserted into the right internal jugular vein and guided through the right ventricle into the main pulmonary artery to measure mean pulmonary arterial pressure. Correct positioning of the pulmonary artery catheter was determined from the shape of the pressure tracing displayed on an oscilloscope. Cardiac output was measured by cardiogreen dye dilution (21). These indices were calculated by an online personal computer. Cardiac output was calculated using an algorithm based on the standard Stewart-Hamilton method and normalized to body weight to obtain the cardiac index (22). Blood samples were drawn from the carotid catheter into capillary tubes for measurement of hematocrit.

Four additional groups were studied to determine the effect of ACE inhibition on the hemodynamic and structural changes of pulmonary hypertension. On study day 0 , the rats were anesthetized as above to allow implantation of osmotic minipumps (model 2ML2; Alza Corp., Palo Alto, CA) through an incision into the peritoneal cavity. These pumps deliver a continuous intraperitoneal infusion at a constant rate of $\sim 0.5 \mu \mathrm{l} / \mathrm{h}$ for $14 \mathrm{~d}$. Pumps were primed with the ACE inhibitor, captopril $(20 \mathrm{mg} / \mathrm{kg} / \mathrm{d})$, dissolved in PBS. Control groups received PBS alone. In normoxic rats, at the end of a 2-wk period of chronic administration, this dose of captopril was found to reduce the systemic pressor response to an intravenous bolus of $100 \mathrm{ng}$ angiotensin I from $28 \pm 2.2 \mathrm{mmHg}(n=6)$ in saline-treated rats to $9.4 \pm 1.2 \mathrm{mmHg}(n$ $=10)$ in animals receiving captopril $(P<0.05)$. After recovery from anesthesia, experimental animals were placed in the hypobaric hypoxic chamber for $14 \mathrm{~d}$ to induce hypoxic pulmonary hypertension. Captopril or saline was also administered to groups of normoxic control animals which were maintained in room air at Denver altitude $(640 \mathrm{mmHg})$.

On study day 12, animals were again anesthetized for insertion of indwelling jugular, carotid, and pulmonary artery catheters as described above. Two further catheters were placed in the right jugular for blood sampling and drug administration. Catheters were exteriorized to the back of the neck for accessibility during subsequent hemodynamic studies. On recovery from anesthesia, hypoxic animals were returned to the hypobaric hypoxic chamber for a further $2 \mathrm{~d}$.

On study day 14, 1-2 h after removal from the hypobaric chamber, conscious rats were studied in a small Plexiglas chamber flushed continuously with room air and measurements were made of mean pulmonary artery pressure, mean systemic arterial pressure, and cardiac output.

Assessment of right ventricular hypertrophy. After hemodynamic studies, the thorax was opened and the animal was killed by exsanguination. Blood was taken for measurement of serum ACE activity. An incision was made in the free wall of the right ventricle, through which a cannula was introduced into the pulmonary artery. The pulmonary artery was flushed with $10 \mathrm{ml}$ of PBS to expel blood from the lungs. The heart and lungs were then removed en bloc. The heart was dissected free and the right ventricle was carefully separated from the left ventricle and septum. The ventricles were blotted dry and weighed separately to determine the ratio of the weight of the right ventricle to that of the left ventricle plus septum $(\mathrm{RV} / \mathrm{LV}+\mathrm{S})$.

Processing of lung tissue. To study ACE activity and expression in normoxic and hypoxic rats, the left lung was separated from the right and a cannula was tied into the left main bronchus. This lung was then fixed in inflation with $10 \%$ formalin at $36 \mathrm{~cm} \mathrm{H}_{2} \mathrm{O}$ for $24 \mathrm{~h}$ for histology and in situ hybridization studies. The formalin-fixed tissue was trans- ferred to $70 \%$ ethanol before paraffin embedding and sectioning. The $5-\mu \mathrm{m}$-thick sections were stained with hematoxylin and eosin. For immunohistochemical studies the right cardiac lobe was inflated with a solution of $30 \%$ sucrose and $50 \%$ embedding medium for frozen tissue specimens (Tissue-Tek ${ }^{\circledR}$ OCT Compound; Miles Inc., Elkhart, IN), placed in a cryomold ( Tissue-Tek ${ }^{\circledR}$ ), and covered with embedding medium, then immediately frozen in hexane cooled by dry ice in ethanol. The remaining right lung was snap frozen in liquid nitrogen and stored at $-70^{\circ} \mathrm{C}$ for estimation of ACE activity.

In rats studied to examine the effects of ACE inhibition on pulmonary hypertension, a cannula was tied into the main pulmonary artery and flushed through with $10 \mathrm{ml} \mathrm{PBS}$ at $37^{\circ} \mathrm{C}$. A mixture of barium sulfate and gelatin was then infused into the pulmonary artery at a pressure of $76 \mathrm{mmHg}$ at $60^{\circ} \mathrm{C}$ for $5 \mathrm{~min}(1)$. The trachea was then cannulated and the lungs were fixed at a constant inflation pressure of $36 \mathrm{cmH}_{2} \mathrm{O}$ with $10 \%$ formalin for $24 \mathrm{~h}$. Lung sections were cut parallel to the hilum and stained with hematoxylin and eosin and Verhoef-van Gieson stains.

Pulmonary artery morphometry. To assess the degree of medial thickening of muscular pulmonary arteries, 5-s video light microscopy recordings were made of barium-filled vessels in Verhoef-van Giesonstained lung sections. Images of $\sim 40$ to 50 vessels per section were recorded in subsets of animals at a magnification of 400 . Each artery was classified by the structure of the accompanying airway as terminal bronchiole, respiratory bronchiole, alveolar duct, or alveolar wall. The video images were captured onto a computer (Framegrabber 3.1; RasterOps Corp., Santa Clara, CA) where measurements were made of wall thickness. A computer program (Image 1.35; National Institutes of Health, Bethesda, MD) was used to measure mean arterial diameter (between external elastic laminae) and medial thickness (between internal and external elastic laminae) in completely muscular arteries which accompanied terminal and respiratory bronchioles. Mean arterial diameter in arteries which were not circular in cross-section was defined as the mean of two diameters measured perpendicular to each other, one of which being the greatest diameter. The width of the media was measured at four points around the circumference of each artery, one in each of the four quadrants defined by the perpendicular lines used to measure diameter. Medial width was expressed as a percentage of arterial diameter, by the formula: percent wall thickness $=(2 \times$ medial thickness) $\times 100$ /external diameter.

The effect of captopril on the abnormal extension of smooth muscle into usually nonmuscular alveolar wall and alveolar duct vessels, which occurs during chronic hypoxia (1), was assessed as follows: each barium-containing vessel identified was viewed at a magnification of 400 and the structure of each vessels was then noted as muscular, partially muscular, or nonmuscular. This analysis was performed by a single observer who was unaware of the experimental conditions pertaining to each section at the time of interpretation.

Estimation of lung, kidney, and serum ACE activity. Changes in ACE activity during hypoxic exposure are known to be organ specific (19). We followed the time course of lung, renal, and serum ACE activity during hypoxia at shorter intervals than previous workers to gain insight into potential mechanisms of altered lung ACE activity, since elevated serum ACE may reflect increased shedding from the pulmonary vascular endothelium (23).

Lung, kidneys, and serum were stored at $-70^{\circ} \mathrm{C}$ before assay of ACE activity. ACE activity in lungs from control and hypoxic rats was measured by the rate of generation of His-Leu from each of two ACE substrates: Hip-His-Leu and Z-Phe-His-Leu, using a fluorometric assay $(24,25)$. These two substrates are metabolized to different extents by two active sites on the ACE molecule (26). Hip-His-Leu is hydrolyzed approximately nine times faster by the $\mathrm{C}$-domain than the $\mathrm{N}$-domain of ACE (27), whereas Z-Phe-His-Leu is almost equally hydrolyzed by both domains (26). By using both substrates we hoped to ascertain whether hypoxia exerted differential effects on these active sites. For this assay, frozen lung was thawed and homogenized (Tekmar ${ }^{\circledR}$ Tissumizer, Tekmar Co., Cincinnati, $\mathrm{OH}$ ) in saline at $4^{\circ} \mathrm{C}$ at a ratio of $1: 10$ (wt/ vol). Homogenate was then diluted 1:100 in the Tris buffer appropriate 
to each substrate (see below). $10 \mu \mathrm{l}$ of the diluted homogenate was added to $200 \mu \mathrm{l}$ of buffered substrate and incubated under standard assay conditions for $30 \mathrm{~min}$ : for hydrolysis of Hip-His-Leu: $5 \mathrm{mM}$ substrate, $100 \mathrm{mM}$ Tris, $\mathrm{pH} 8.3,600 \mathrm{mM} \mathrm{NaCl}$ at $37^{\circ} \mathrm{C}$; for hydrolysis of Z-Phe-His-Leu: $0.5 \mathrm{mM}$ substrate, $50 \mathrm{mM}$ Tris, pH 7.5, $150 \mathrm{mM}$ $\mathrm{NaCl}$ at $37^{\circ} \mathrm{C}$. The reaction was then stopped by the addition of $1.5 \mathrm{ml}$ $0.28 \mathrm{~N} \mathrm{NaOH}$. $o$-phthalaldehyde ( $1 \mathrm{mg}$ in $100 \mu \mathrm{l}$ methanol) was added for $10 \mathrm{~min}$ before stopping this reaction with $200 \mu \mathrm{l} 2 \mathrm{~N} \mathrm{HCl}$. The fluorescence of the samples was measured with a fluorescence spectrometer (model 650-10S; Perkin-Elmer Corp., Norwalk, CT) at an emission wavelength of $500 \mathrm{~nm}$ and an excitation wavelength of $363 \mathrm{~nm}$. Samples were run in duplicate and included blanks (consisting of all reagents apart from lung homogenate), His-Leu standards, and samples incubated in the presence of the ACE inhibitor, captopril. The dilution of lung homogenate chosen (1:100) gave optimal fluorescent signal while maintaining initial reaction rate conditions (25). The results were expressed as milliUnits per milligram of protein, where $1 \mathrm{mU}$ is $1 \mathrm{nmol} \mathrm{His-Leu/}$ $\mathrm{min} / \mathrm{ml}$. Protein concentration was determined in the homogenates with a protein assay kit (Bio-Rad Laboratories, Hercules, CA) and quantitated by comparison to a standard curve for bovine serum albumin.

The normally low level of renal ACE activity (28) was assayed in a tissue membrane preparation, to avoid contamination by free ACE in serum. The presence of residual serum in lung homogenate would not significantly affect the estimation of lung ACE activity which is $\sim 100$ times greater ( $w t / w t)$ than serum ACE activity. Kidneys were homogenized at $4^{\circ} \mathrm{C}$ in a 10 -fold excess of Tris buffer $(0.05 \mathrm{M}, \mathrm{pH} 7.4)$. The crude homogenate was centrifuged at $1,000 \mathrm{~g}$ for $15 \mathrm{~min}$ at $4^{\circ} \mathrm{C}$, and the resulting supernatant was submitted to another centrifugation at $16,000 \mathrm{~g}$ for $30 \mathrm{~min}$ at $4^{\circ} \mathrm{C}$ to yield the particulate fraction containing cell membranes. The pellet was washed superficially with $5 \mathrm{ml}$ cold assay buffer, then resuspended in $500 \mu \mathrm{l}$ of fresh buffer containing the detergent, Nonidet P-40 (1\%), sonicated $2 \times 10 \mathrm{~s}$, centrifuged at 300 $g$ for $10 \mathrm{~min}$, and the supernatant was assayed for ACE activity. Supernatant was diluted $1: 4$, then $10 \mu \mathrm{l}$ was added to $200 \mu \mathrm{l}$ of $0.5 \mathrm{mM}$ Z-PheHis-Leu, $50 \mathrm{mM}$ Tris, pH 7.5, $150 \mathrm{mM} \mathrm{NaCl}$ at $37^{\circ} \mathrm{C}$ for $45 \mathrm{~min}$. The remainder of the assay proceeded as described above for lung. Renal ACE activity was expressed as milliUnits per milligram of protein.

Serum was diluted 1:9 for assay of ACE activity in $50 \mathrm{mM}$ Tris, $\mathrm{pH} 7.5,150 \mathrm{mM} \mathrm{NaCl} .10 \mu \mathrm{l}$ of diluted serum was added to $0.5 \mathrm{mM}$ substrate (Z-Phe-His-Leu) in $50 \mathrm{mM}$ Tris, $\mathrm{pH} 7.5,150 \mathrm{mM} \mathrm{NaCl}$ and incubated at $37^{\circ} \mathrm{C}$ for $30 \mathrm{~min}$. The assay was then continued as for lung ACE. Serum ACE activity was expressed as milliUnits per milliliter of serum.

The specificity of the assay for ACE activity was confirmed by the absence of fluorometric signal when $10^{-6} \mathrm{M}$ captopril was added to the initial incubation of substrate with sample.

Immunohistochemistry. A monoclonal antibody to ACE (9B9) was used $(29,30)$ to investigate the distribution of ACE antigen in the pulmonary circulation before and during the development of hypoxic pulmonary hypertension. Cryostat sections of frozen tissue were cut ( 4 $\mu \mathrm{m}$ thick) and fixed in $1 \%$ formaldehyde for $1 \mathrm{~min}$ followed by acetone for $5 \mathrm{~min}$ at room temperature. Both immunofluorescent and alkaline phosphatase anti-alkaline phosphatase (APAAP) techniques were used to visualize $\mathrm{ACE}$ antigen.

For immunofluorescence, sections were incubated with $12.5 \%$ rat serum for $15 \mathrm{~min}$ to reduce nonspecific binding. Sections were then treated in the following sequence: with primary anti-ACE monoclonal antibody ( $10 \mu \mathrm{g} / \mathrm{ml})$; biotinylated anti-mouse IgG ( $1: 40)$; streptavidinconjugated Texas red (TR) (1:50). These incubations were carried out for $1 \mathrm{~h}$ at room temperature with intervening washes in PBS (pH 7.4) $(3 \times 5 \mathrm{~min})$. Sections were then rinsed in distilled water, mounted in aqueous mounting medium (Aqua-mount ${ }^{\circledR}$; Lerner Labs, Pittsburgh, PA), and examined on a Nikon Optiphot epifluorescence photomicroscope. Sections treated with all steps except the primary antibody or control mouse ascitic fluid in place of the primary antibody served as controls.

ACE antigen was also visualized by the APAAP technique as described previously (30). Briefly, sections were incubated with $12.5 \%$ rat serum in Tris $(50 \mathrm{mM}, \mathrm{pH} 7.6)$ buffered saline to reduce nonspecific binding of antibodies, then with the primary anti-ACE monoclonal antibody for $1 \mathrm{~h}$. This was followed by an incubation with rabbit antimouse "link" IgG (1:40), then with monoclonal APAAP complex (1:50) for $30 \mathrm{~min}$ each. Incubations with rabbit anti-mouse IgG and APAAP were then repeated for $10 \mathrm{~min}$ each. All incubations were supplemented with $12.5 \%$ pooled rat serum. Samples were thoroughly washed in Tris-buffered saline between steps. Bound alkaline phosphatase was visualized by a 20 -min incubation with new fuchsin $(100 \mu \mathrm{g} /$ $\mathrm{ml})$ plus levamisole $(400 \mu \mathrm{g} / \mathrm{ml})$ to yield a red reaction product. Sections were counterstained with hematoxylin before mounting.

We used a semiquantitative analysis to differentiate degrees of ACE expression with the APAAP technique, as suggested by F. Franke (Institute of Pathology, Giessen, Germany) (31). A range of doubling dilutions of ACE antibody was found which allowed lung vascular ACE to be detected with maximum signal at one end of the range and complete extinction of signal at the other. The range of doubling dilutions of antibody was found empirically to be from 2 to $0.03 \mu \mathrm{g} / \mathrm{ml}$. Serial lung sections from normoxic and 8- or 14-d hypoxic rats were processed together and stained with the range of primary antibody dilutions to allow comparison of signal between groups. Arteries were identified and landmarked according to the accompanying airway as preacinar, or related to terminal bronchioles, respiratory bronchioles, alveolar ducts, or alveolar wall. Thus ACE expression in a category of artery could be defined in terms of the dilution of antibody at which signal could still just be detected.

In situ hybridization. In situ hybridization studies were performed on formalin-fixed lung sections from three groups of rats: control, 8-d hypoxic, and 14-d hypoxic ( $n=5$ per group). Sections were cut at 5 $\mu \mathrm{m}$, picked up on Superfrot Plus slides (Fisher Scientific, Pittsburgh, PA), deparaffinized in xylene, dehydrated through graded ethanols, and rehydrated in PBS. All sections were treated with $1 \mu \mathrm{g} / \mathrm{ml}$ nucleasefree proteinase $\mathbf{K}$ to loosen the constraints of intracellular crosslinks caused by aldehyde fixation and were washed in freshly prepared 0.1 $\mathrm{M}$ triethanolamine buffer containing $0.25 \%$ acetic anhydride to reduce potential nonspecific binding sites. Sections were covered with $35 \mu$ l of hybridization buffer containing $50 \%$ deionized formamide, $2 \times$ SSC $(1 \times$ is $150 \mathrm{mM} \mathrm{NaCl}, 15 \mathrm{mM}$ sodium citrate, $\mathrm{pH} 7.0$ ), $20 \mathrm{mM}$ Tris$\mathrm{HCl}, \mathrm{pH} 8.0,1 \times$ Denhardt's solution, $1 \mathrm{mM}$ EDTA, $10 \%$ dextran sulfate, $100 \mathrm{mM}$ DTT, $0.5 \mathrm{mg} / \mathrm{ml}$ yeast RNA, and $1 \times 10^{6} \mathrm{cpm}$ of ${ }^{35} \mathrm{~S}$-labeled ACE RNA probe. To retain the hybridization solution, sections were covered with a piece of Parafilm (American National Can Co., Greenwich, CT). Sections were incubated at $55^{\circ} \mathrm{C}$ for $18 \mathrm{~h}$ in a humidified chamber.

After hybridization, slides were washed under conditions previously described (4), except that $10 \mathrm{mM}$ DTT was substituted for $25 \mathrm{mM} \beta$ mercaptoethanol in the wash solutions. Nonspecific binding was reduced by incubating the slides in $0.5 \mathrm{M} \mathrm{NaCl}, 10 \mathrm{mM}$ Tris- $\mathrm{HCl}, \mathrm{pH} 8.0,1$ mM EDTA containing $20 \mu \mathrm{g} / \mathrm{ml}$ RNase-A at $37^{\circ} \mathrm{C}$ for $30 \mathrm{~min}$. Washed slides were dipped in Kodak NTB-2 emulsion diluted 1:1 with distilled water and processed for autoradiography as previously described (4). Slides were exposed for $14 \mathrm{~d}$ at $4^{\circ} \mathrm{C}$. After development of the photographic emulsion, slides were stained with hematoxylin and eosin. Silver grains were visualized by dark-field microscopy.

Preparation of ACE cRNA probe. Mouse ACE cDNA (3,800 bp) cloned into the plasmid vector Bluescript $\mathrm{KS}^{+}$(provided by Dr. K. Bernstein, Emory University, Atlanta, GA) was used to prepare a cRNA probe for in situ hybridization studies. The plasmid was linearized with BamH1 or XhoI for antisense and sense cRNA, respectively. In vitro transcription from the plasmid $\mathrm{T} 3$ promoter yielded antisense probe and from the $\mathrm{T} 7$ promoter yielded sense probe. Transcripts were labeled with ${ }^{35}$ S-UTP ( $>1,200 \mathrm{Ci} / \mathrm{mM}$; New England Nuclear, Boston, MA) under conditions recommended by and with reagents from Promega (Madison, WI), except that the transcription reaction was extended to $4 \mathrm{~h}$ to allow for the relatively inefficient incorporation of sulfated ribonucleotides. Calculated probe-specific activities were between $10^{8}$ and $10^{9} \mathrm{dpm} / \mu \mathrm{g}$. RNA probes were prepared and purified as previously described (4). Both sense and antisense transcripts were cut down to 
Table I. Hematocrits, Cardiac Indices, RV/LV+S Ratios, and Mean Pulmonary Artery Pressures in Normoxic Control, 8- and 14-d Hypoxic Rats

\begin{tabular}{lccccc}
\hline \multicolumn{1}{c}{ Group } & $n$ & Hematocrit & Cardiac index & RV/LV+S & MPAP \\
\hline & & $\%$ & Liters/min $/ k$ & & $m m H^{2}$ \\
Normoxic control & 6 & $48 \pm 0.8$ & $0.261 \pm 0.01$ & $0.264 \pm 0.02$ & $17.8 \pm 0.5$ \\
Hypoxic 8 d & 6 & $60 \pm 0.9^{*}$ & $0.323 \pm 0.02$ & $0.407 \pm 0.01^{*}$ & $25.9 \pm 1^{*}$ \\
Hypoxic 14 d & 6 & $61 \pm 0.3^{*}$ & $0.236 \pm 0.02$ & $0.538 \pm 0.02^{*}$ & $31.2 \pm 1.8^{*}$ \\
\hline
\end{tabular}

$R V / L V+S$, ratio of weight of right ventricle to that of left ventricle plus septum; $n$, number of animals; MPAP, mean pulmonary artery pressure. ${ }^{*} P<0.05$ compared with normoxic saline group.

$\sim 500 \mathrm{bp}$ for in situ studies by limited alkaline hydrolysis as described by Angerer and Angerer (32). Briefly, the radiolabeled probe was dissolved in $50 \mu \mathrm{l}$ of distilled water and the $\mathrm{pH}$ was adjusted to 10.2 by addition of $30 \mu \mathrm{l} 0.2 \mathrm{M} \mathrm{Na}_{2} \mathrm{CO}_{3}$ and $20 \mu \mathrm{l} 0.2 \mathrm{M} \mathrm{NaHCO}_{3}$. This solution was incubated at $60^{\circ} \mathrm{C}$ for $16 \mathrm{~min}(32)$. The hydrolysis was then terminated by adding $3 \mu \mathrm{l} 3 \mathrm{M}$ sodium acetate, $\mathrm{pH} 6.0$, and $5 \mu \mathrm{l}$ $10 \%$ glacial acetic acid. The hydrolyzed probe was precipitated by addition of $10 \mu \mathrm{l}$ yeast tRNA carrier and $2.5 \mathrm{vol}$ ethanol, then resuspended in $50 \mu \mathrm{l} 10 \mathrm{mM}$ Tris-HCl, $20 \mathrm{mM}$ DTT, $1 \mathrm{mM}$ EDTA, pH 8.0 . The size of the hydrolyzed labeled probe was confirmed by autoradiography after electrophoresis in a denaturing $1 \%$ agarose gel.

Reagents and antibodies. Hip-His-Leu, His-Leu, angiotensin I, Nonidet P-40, captopril, biotinylated anti-mouse IgG, control mouse ascitic fluid, levamisole, nuclease-free proteinase $\mathrm{K}$, and RNase-A were obtained from Sigma Chemical Co. (St. Louis, MO); Z-Phe-His-Leu was from Crescent Chemical Co. (Hauppauge, NY); o-phthalaldehyde was from Serva (Heidelberg, Germany); streptavidin-conjugated TR was from Amersham Corp. (Arlington Heights, IL); monoclonal APAAP complex and rabbit anti-mouse IgG were from DAKO (Glostrup, Denmark); and new fuchsin substrate was from BioGenex Labs (San Ramon, CA).

Statistical analysis. Results are expressed as mean \pm SEM. One-way

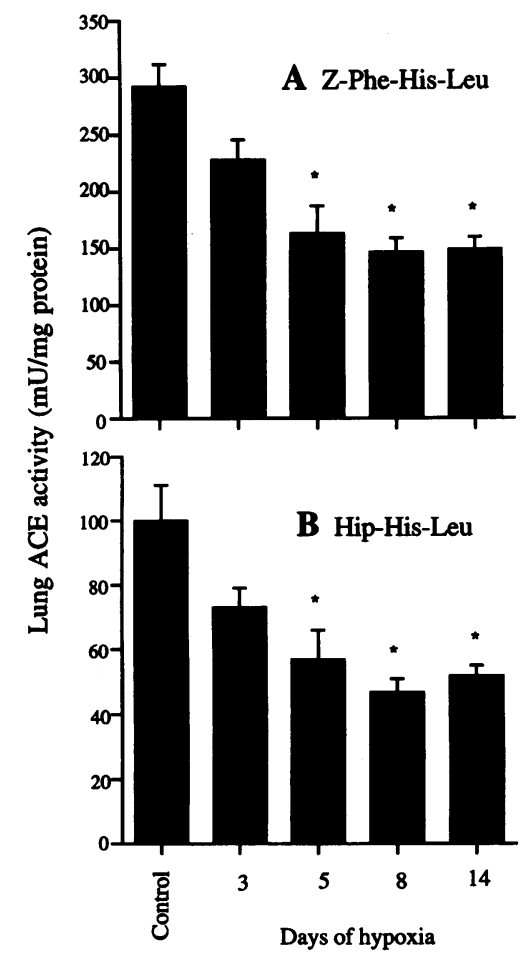

Figure 1. Bar graph of lung ACE activity assayed with the substrates Z-Phe-His-Leu $(A)$ and Hip-His-Leu $(B)$ showing the reduction in lung ACE activity in groups ( $n=6$ per group) of rats maintained in hypoxia for up to $14 \mathrm{~d}$. $* P<0.05$ compared with control.
ANOVA was used to compare means between groups with Duncan New Multiple Range test to establish significant differences. A $P<0.05$ was taken to indicate that conventional statistical significance had been achieved.

\section{Results}

Pulmonary hypertension. 8 and $14 \mathrm{~d}$ of hypobaric hypoxia caused pulmonary hypertension as evidenced by elevated mean pulmonary artery pressures in these animals compared with control normoxic rats (Table I). Right ventricular hypertrophy accompanied the pressure changes, and the ratio $\mathrm{RV} / \mathrm{LV}+\mathrm{S}$ had approximately doubled by $14 \mathrm{~d}$ of hypoxia (Table I). As expected, the hematocrit was elevated at 8 and $14 \mathrm{~d}$ of hypoxia (Table I).

Examination of hematoxylin and eosin-stained sections by light microscopy showed increased wall thickness of muscular arteries and distal spread of muscle into normally nonmuscular pulmonary arterioles by 8 and $14 \mathrm{~d}$ of hypoxia (see below).

Biochemical estimation of ACE activity in lung, serum, and kidney. We estimated ACE activity with two substrates, hydrolyzed to different extents by the two active sites at the amino and carboxy termini of the ACE molecule, to determine whether the effect of chronic hypoxia on ACE enzymatic activity is specific to one or the other active site. We found that chronic hypoxia caused a reduction in lung ACE activity, the time course of which is shown in Fig. 1. By $5 \mathrm{~d}$ of hypoxia, lung ACE activity had fallen to $\sim 50 \%$ of the control activity, as measured with either substrate. The percent reduction in lung ACE activity was similar at each time point with either substrate, indicating that the reduced activity was not due to a selective effect of hypoxia on the $\mathrm{COOH}$ - or $\mathrm{NH}_{2}$-terminal active sites.

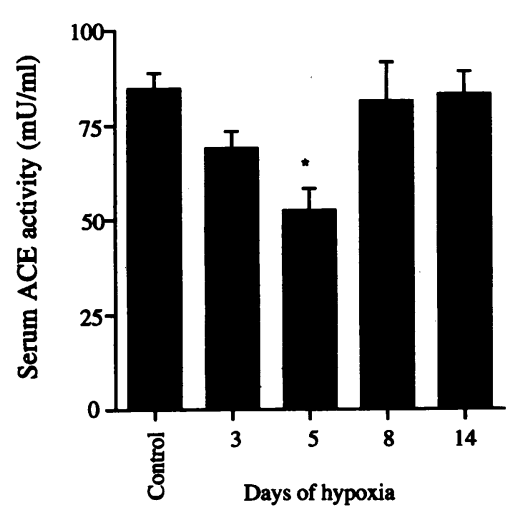

Figure 2. Bar graph showing the biphasic change in serum ACE activity assayed with 2Phe-His-Leu in groups ( $n=6$ per group) of rats maintained in hypoxia for up to $14 \mathrm{~d}$. $* P<0.05$ compared with control. 


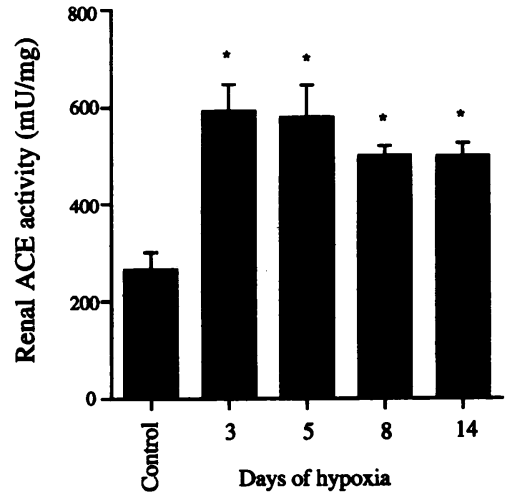

Figure 3. Bar graph showing the increase in renal membrane ACE activity assayed with 2Phe-His-Leu in groups ( $n=6$ per group) of rats maintained in hypoxia for up to $14 \mathrm{~d} . * P<0.05$ compared with control.

The observed reduction in lung ACE activity could have been due to increased shedding of ACE antigen from the pulmonary endothelium or a reduction in ACE production or processing. To determine whether shedding of ACE from the pulmonary vascular endothelium was a likely mechanism for the reduction in total lung ACE activity, we measured serum $A C E$ activity at the same time points, since elevated serum ACE accompanied by reduced lung ACE activity has been associated

with pulmonary endothelial injury $(23,33)$. We found that serum ACE activity fell in parallel with lung ACE activity until $5 \mathrm{~d}$ of hypoxia (Fig. 2), suggesting reduced production of lung ACE, rather than increased shedding, as a likely mechanism for reduced total lung ACE activity at least during the first $5 \mathrm{~d}$ of chronic hypoxia. By 8 and $14 \mathrm{~d}$ of hypoxia, serum ACE activity had returned to control levels (Fig. 2). To determine whether changes in the ACE activity of other organs could contribute to the return of serum ACE to normal levels, we followed changes in renal ACE activity. Fig. 3 shows that renal ACE activity was increased after only $3 \mathrm{~d}$ of hypoxia and remained elevated at all subsequent time points studied.

Immunohistochemical study of ACE expression. To determine the site of reduced lung ACE activity and to establish whether local increases in pulmonary vascular ACE expression occurred during chronic hypoxia, we assessed the distribution of ACE antigen by immunohistochemistry. TR immunofluorescence allowed ready visualization of ACE antigen in the endothelial cells of the alveolar capillaries. Alveolar capillary endothelial staining by ACE-TR immunofluorescence was intense in normoxic rats (Fig. $4 \mathrm{~A}$ ). In contrast, by 8 and $14 \mathrm{~d}$ of hypoxia, alveolar capillary staining was markedly reduced. However, the endothelial staining of small arteries stood out prominently against the alveolar stain (Fig. $4, B$ and $C$ ). The
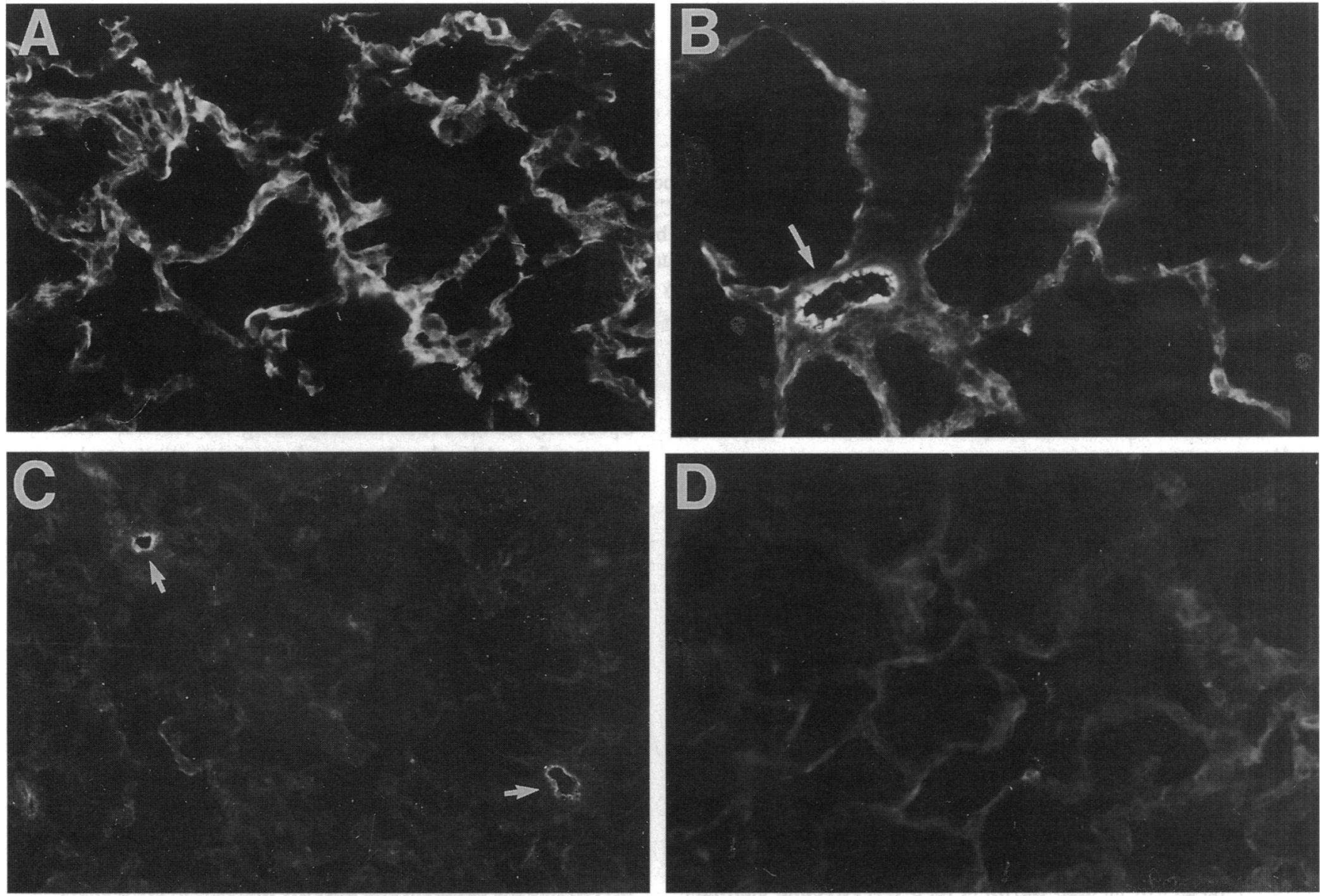

Figure 4. Intensity of ACE immunofluorescence (TR) staining in alveolar capillaries in normoxic rat lung and in lungs of rats exposed to chronic hypoxia. Lung sections were incubated with a monoclonal antibody to human ACE $(A-C)$ or control mouse $\operatorname{IgG}(D)$. Normoxic lung demonstrated intense staining of the alveolar capillary endothelium $(A)$ which was markedly reduced by $8 \mathrm{~d}$ of hypoxia $(B$ and $C)$. ACE staining of the endothelium of small pulmonary arteries was prominent in the hypoxic rats (arrows) $(B$ and $C$ ). The staining was specific since virtually no signal was seen in the normoxic lung incubated with control mouse $\operatorname{IgG}(D) . A, B$, and $D$, original magnification $\times 400 ; C, \times 100$. 

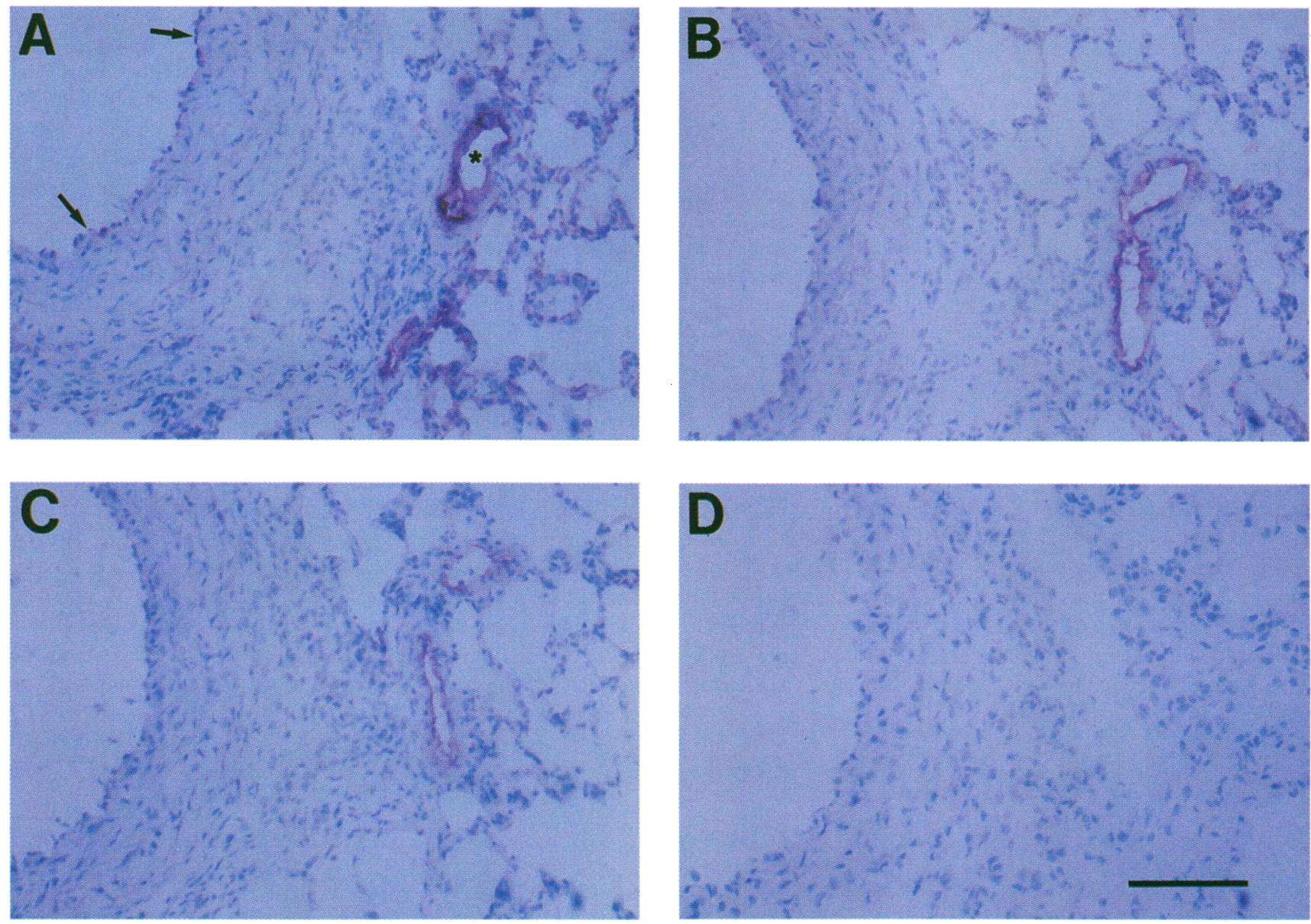

Figure 5. Longitudinal variation in intensity of ACE expression in the normal pulmonary vasculature. Serial frozen sections of normal rat lung stained with increasing dilutions of monoclonal anti-ACE antibody $(A-C)$ or control mouse $\operatorname{IgG}(D)$. At an antibody dilution of $2 \mu \mathrm{g} / \mathrm{ml}(A) \mathrm{ACE}$ signal was seen in the endothelium (arrows) of large muscular arteries but was not detected at higher dilutions $(B$ and $C$ ). Alveolar capillaries remained positive for ACE at an antibody dilution of $0.5 \mu \mathrm{g} / \mathrm{ml}(B)$, but not at $0.25 \mu \mathrm{g} / \mathrm{ml}(C)$, when only small muscular arteries remained positive for ACE $(C)$. The specificity of ACE staining was confirmed by the absence of signal when sections were stained with control mouse IgG (D). Bar, $\sim 100 \mu \mathrm{m}$.

specificity of this stain was confirmed by the finding of a very low level of background staining with control mouse IgG (Fig. $4 D$ ).

Since the fluorescence technique strongly suggested increased ACE expression in small pulmonary arteries during chronic hypoxia, we used the APAAP technique, which enabled us to better characterize vessel wall structure and allowed estimation of relative levels of ACE expression, to investigate this further.

Using this method we first made the observation that a marked longitudinal variation clearly existed in the level of ACE expression in the normal pulmonary vasculature (Fig. 5). In larger preacinar arteries, endothelial ACE was just detectable at high concentrations of antibody $(1-2 \mu \mathrm{g} / \mathrm{ml}$ ) (Fig. $5 A$ ) but became undetectable at lower concentrations $(0.5 \mu \mathrm{g} / \mathrm{ml})$ (Fig. $5 B$ ). On the other hand, in small intraacinar muscular arteries (Fig. 5, $A-C$ ) ACE staining remained intense at antibody concentrations as low as $0.25 \mu \mathrm{g} / \mathrm{ml}$ (Fig. $5 C$ ). Alveolar capillary staining was still present at antibody concentrations of $0.5 \mu \mathrm{g} /$ $\mathrm{ml}$ (Fig. 5 B) but was undetectable at $0.25 \mu \mathrm{g} / \mathrm{ml}$ (Fig. $5 C$ ). The intensely staining small muscular arteries in the normal rat usually accompanied terminal and respiratory bronchioles. In all arteries in normoxic rats ACE staining was clearly internal to the internal elastic lamina and thus confined to the endothelium. Specificity of the ACE antibody using the APAAP technique was confirmed by the absence of staining with control mouse IgG (Fig. 5 D).

A localized and specific increase in ACE expression was observed in small pulmonary arteries accompanying alveolar ducts and walls in chronically hypoxic rats. Whereas in normoxic rats nonmuscular alveolar duct and wall vessels tended to lose their ACE staining at the same antibody dilution as alveolar capillary ACE (Fig. 6, $A$ and $B$ ), by 8 and $14 \mathrm{~d}$ of hypoxia these small vessels were usually partly or completely muscularized and demonstrated intense ACE staining compared with normoxic rats (Fig. 6, $C$ and $D$ ). During hypoxia, no change was observed in the level of ACE expression in large extraacinar arteries and small muscularized arteries at the level of terminal and respiratory bronchioles.

In situ hybridization studies for ACE mRNA. To further investigate the apparent site-specific increase in ACE expression in the small pulmonary arteries of chronically hypoxic, hypertensive rats we performed in situ hybridization studies for ACE mRNA. In hypoxic animals, increased signal for ACE mRNA was seen in small arteries at the level of alveolar ducts and walls, consistent with the localized increase in ACE antigen 

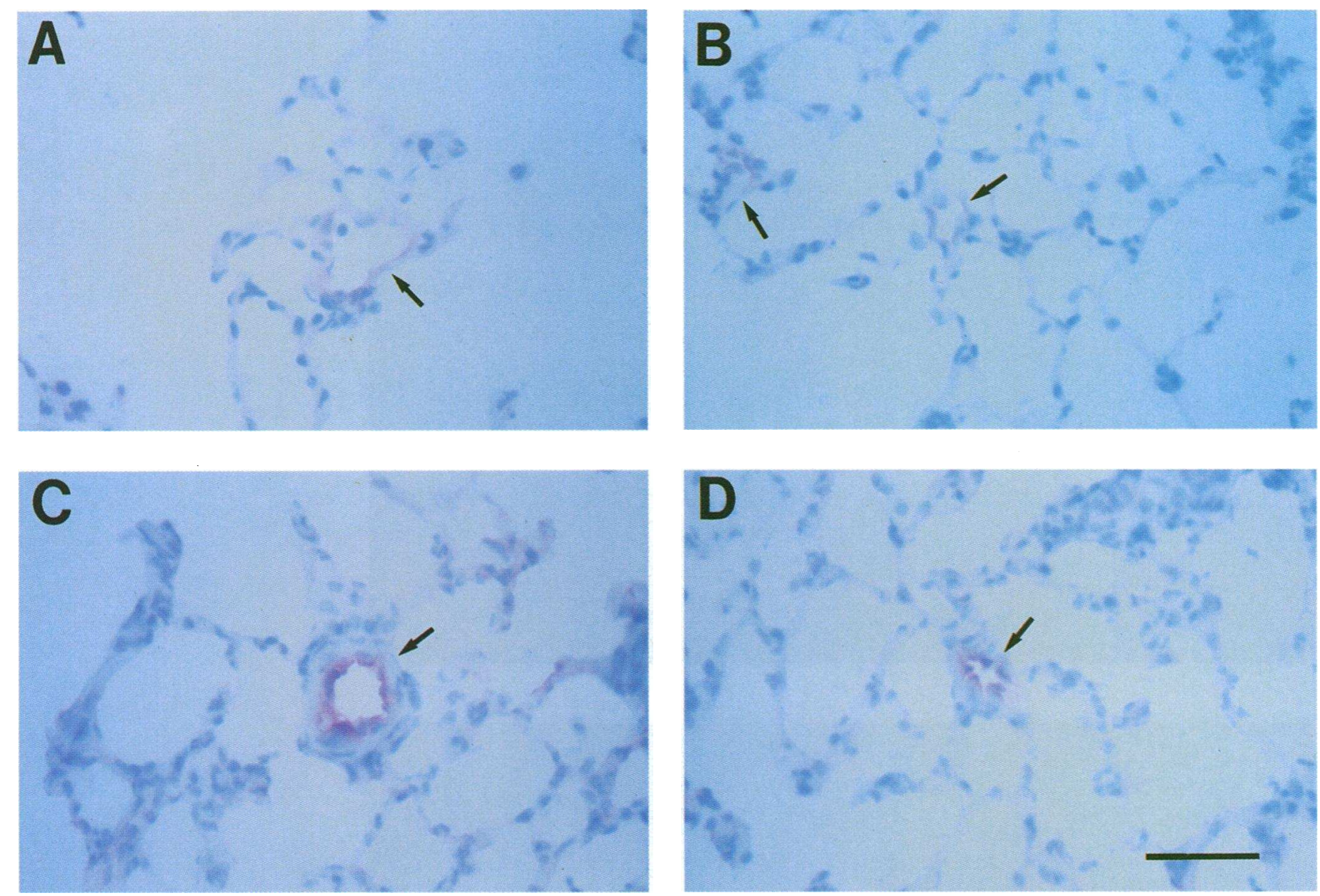

Figure 6. Increased expression of ACE in small pulmonary arteries during chronic hypoxic exposure. Frozen sections of normoxic $(A$ and $B)$ and chronically hypoxic ( $8 \mathrm{~d})(C$ and $D)$ rat lung stained with anti-ACE antibody. All sections were processed in the same batch and stained with an anti-ACE antibody dilution of $0.5 \mu \mathrm{g} / \mathrm{ml}$. Arteries at the level of alveolar ducts $(A$ and $C$ ) and alveolar walls $(B$ and $D)$ showed increased ACE expression and distal muscularization in hypoxic animals. Bar, $\sim 50 \mu \mathrm{m}$.

observed by immunohistochemistry (Fig. 7). In many of these vessels ACE mRNA expression was not confined to the endothelium but was also evident in cells deep to the endothelium (Fig. $7 B$ ). Specificity of this signal was confirmed by the absence of cell-specific signal in sections hybridized with sense probe (not shown). Interestingly, in lung sections from normoxic and hypoxic animals hybridized with antisense ACE cRNA, no clear signal was seen over endothelial cells of alveolar capillaries and large preacinar pulmonary arteries and arteries accompanying terminal and respiratory bronchioles. This poor signal for ACE mRNA over normal endothelial cells has been noted by others (34) and has been attributed to the low copy number of this mRNA in pulmonary endothelial cells (35), despite the abundance of the protein.

Attenuation of pulmonary hypertension by ACE inhibition. We questioned whether increased expression of ACE in small pulmonary arteries, at the level of alveolar ducts and walls, might participate in the distal extension of smooth muscle into normally nonmuscular vessels during chronic hypoxia. If so, then inhibition of ACE should attenuate these changes. Thus we administered the ACE inhibitor, captopril, during chronic hypoxia and measured hemodynamic and structural changes, compared with rats treated with saline vehicle.

In hypoxic rats treated for 2 wk with the ACE inhibitor, captopril, a significant reduction in pulmonary arterial pressure and right ventricular hypertrophy was observed compared with rats treated with saline (Table II). The cardiac index did not differ significantly between groups, implying that the reduction in pulmonary artery pressure achieved with captopril was due to a reduction in pulmonary vascular resistance.

Morphological studies demonstrated a reduction in the medial thickening of small muscular arteries accompanying terminal and respiratory bronchioles (Fig. 8) and a marked reduction in the distal extension of smooth muscle into normally nonmuscular arteries associated with alveolar ducts and walls (Fig. 9).

\section{Discussion}

Our main finding of increased ACE mRNA and antigen expression in small pulmonary arteries associated with alveolar ducts and alveolar walls during chronic hypoxic exposure provides a unifying explanation for the paradoxical results of previous studies in chronic hypoxia where ACE inhibitors were found to attenuate pulmonary hypertension (13-15), despite a reduction in total lung ACE activity (16-19). Moreover, the ACE inhibitor, captopril, attenuated the hemodynamic and structural changes of pulmonary hypertension during chronic hypoxia, causing a marked reduction in the distal extension of smooth muscle into normally nonmuscular arteries at the level of alveolar ducts and walls, the sites of increased ACE expression. In 

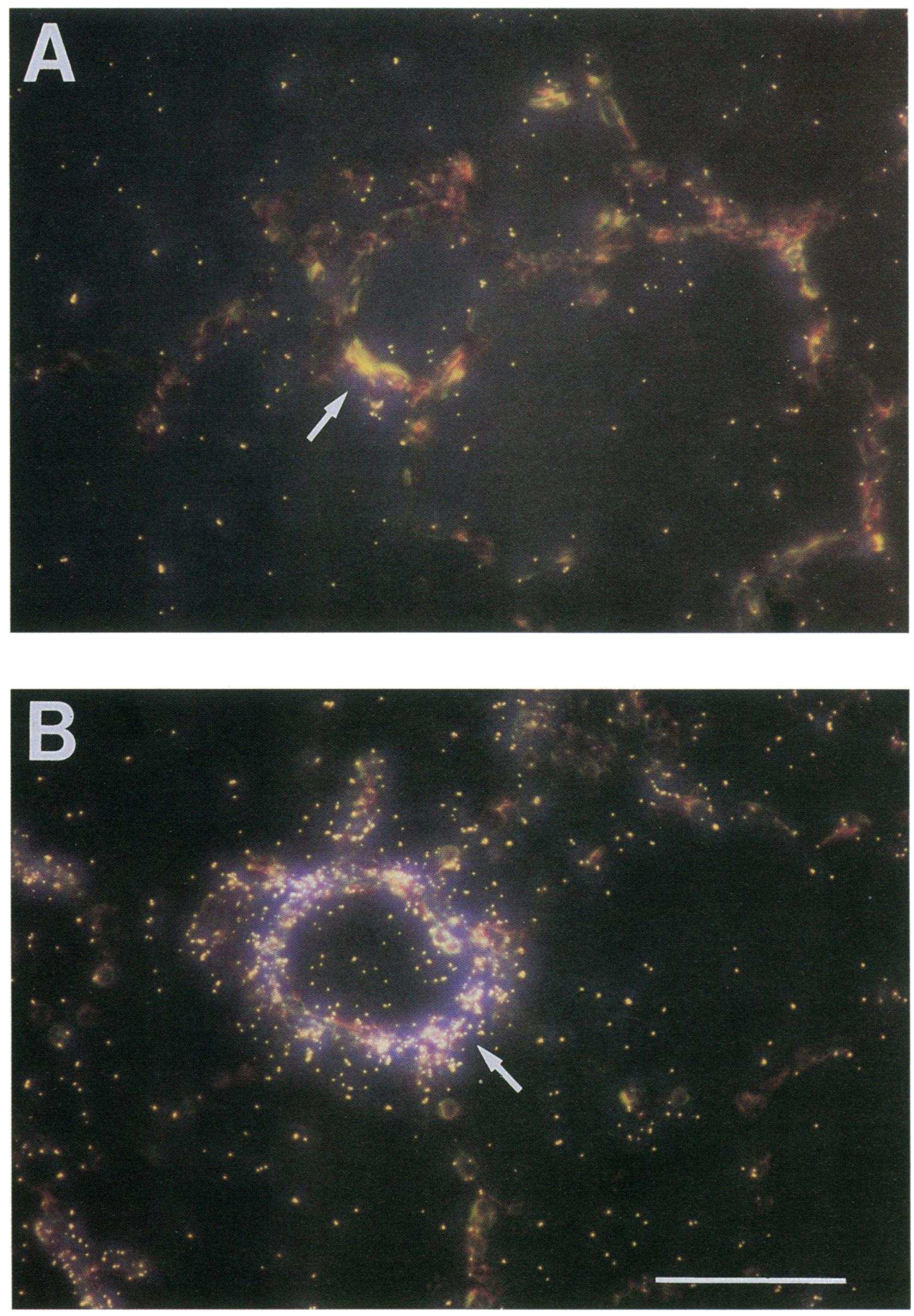

Figure 7. In situ hybridization studies of ACE mRNA expression in normoxic $(A)$ and chronically hypoxic $(B)$ rat lung. Virtually no specific signal (white dots) was seen over alveolar capillaries and small pulmonary arteries (arrow) in normal lung $(A)$. Increased signal for ACE mRNA was observed in the walls of small pulmonary arteries at the level of alveolar ducts and walls in chronically hypoxic rats $(B)$. In hypoxic rats, signal was detected both in endothelial cells and in cells in deeper layers of the vessel wall $(B)$. Bar, $\sim 50 \mu \mathrm{m}$

Table II. Hematocrits, Cardiac Indices, RV/LV+S Ratios, and Mean Pulmonary Artery Pressures in Normoxic Saline Control and Chronically Hypoxic Rats Treated with Saline or Captopril

\begin{tabular}{lccccc}
\hline \multicolumn{1}{c}{ Group } & $n$ & Hematocrit & Cardiac index & RV/LV+S & MPAP \\
& & $\%$ & liters/min $/ k g$ & & $m m H g$ \\
Normoxic saline & 8 & $48 \pm 0.5^{*}$ & $0.321 \pm 0.02$ & $0.303 \pm 0.02^{*}$ & $21 \pm 0.9^{*}$ \\
Hypoxic saline & 8 & $58 \pm 1.5$ & $0.350 \pm 0.03$ & $0.429 \pm 0.01$ & $32.0 \pm 1.4$ \\
Hypoxic captopril & 8 & $57 \pm 1.3$ & $0.332 \pm 0.03$ & $0.360 \pm 0.01^{*}$ & $26.5 \pm 0.7^{*}$ \\
\hline
\end{tabular}

$R V / L V+S$, ratio of weight of right ventricle to that of left ventricle plus septum; $n$, number of animals; MPAP, mean pulmonary artery pressure. $* P<0.05$ compared with hypoxic saline group. 


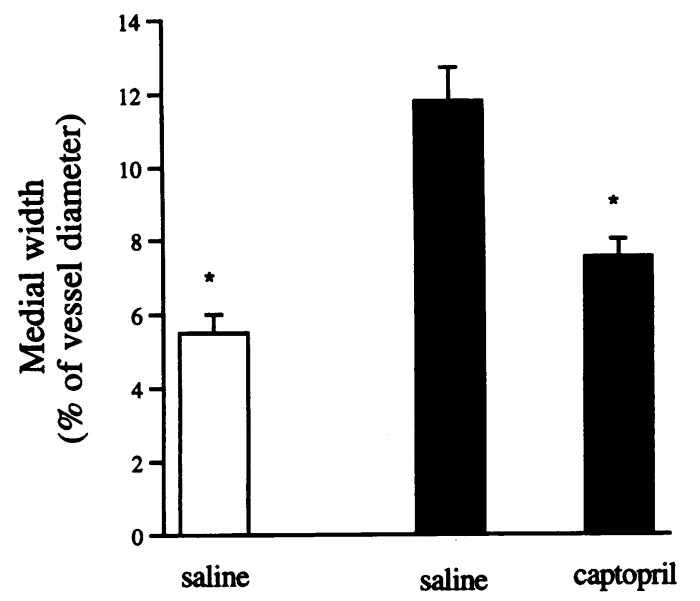

Figure 8. Bar graph showing the medial width of pulmonary arteries (50-100- $\mu \mathrm{m}$ diameter) in normoxic saline-treated rats (open bars) and chronically hypoxic rats treated with saline or captopril (filled bars). Captopril attenuated the medial thickening caused by chronic hypoxia. $* P<0.05$ compared with hypoxic saline-treated rats.

addition we confirmed that ACE activity in whole lung homogenates from hypoxic rats decreased $\sim 50 \%$ by $8 \mathrm{~d}$ of hypoxia, and the reduction in alveolar capillary staining for ACE at this stage suggests a loss of ACE antigen from the alveolar capillary endothelium as a mechanism for the reduction in whole lung ACE activity. Our results suggest that local overexpression of ACE in distal small pulmonary arteries may play a role in the distal muscularization of these vessels, one of the earliest and most consistent features of pulmonary hypertension (36).

The distal spread of smooth muscle into normally nonmuscular pulmonary arteries at the level of alveolar ducts and walls is a feature common to almost all forms of pulmonary hypertension (36), is one of the earliest structural changes in the hypoxic pulmonary vasculature, and correlates closely with a sustained elevation in pulmonary arterial pressure (37). Both ACE immunohistochemistry and in situ hybridization to ACE mRNA indicated that ACE expression was selectively increased in small arteries associated with alveolar ducts and alveolar walls during chronic hypoxia. AII has been reported to cause proliferation $(12,38)$ and hypertrophy $(11)$ of vascular smooth muscle cells. Thus, it is conceivable that increased local vascular ACE expression in small pulmonary arteries, causing increased local production of AII, might stimulate vascular smooth muscle or pericyte proliferation (2) and distal extension of smooth muscle. An alternative explanation is that the extension of vascular smooth muscle stimulated an increase in endothelial ACE expression, since it has been reported that smooth muscle cell conditioned medium stimulates ACE expression by endothelial cells (39). Locally increased production of AII might then promote hypertrophy and/or differentiation (40) of the "new" smooth muscle. Either way, it is likely that AII acts in concert with other locally produced growth factors (41) to promote vascular remodeling. These possibilities require further study in cultured cells.

There are other mechanisms which may induce endothelial ACE expression in the small pulmonary arteries in the setting of hypoxic pulmonary hypertension. Hypoxia per se has been shown to increase pulmonary artery endothelial cell ACE activity in culture $(39,42)$, though others have reported an increase
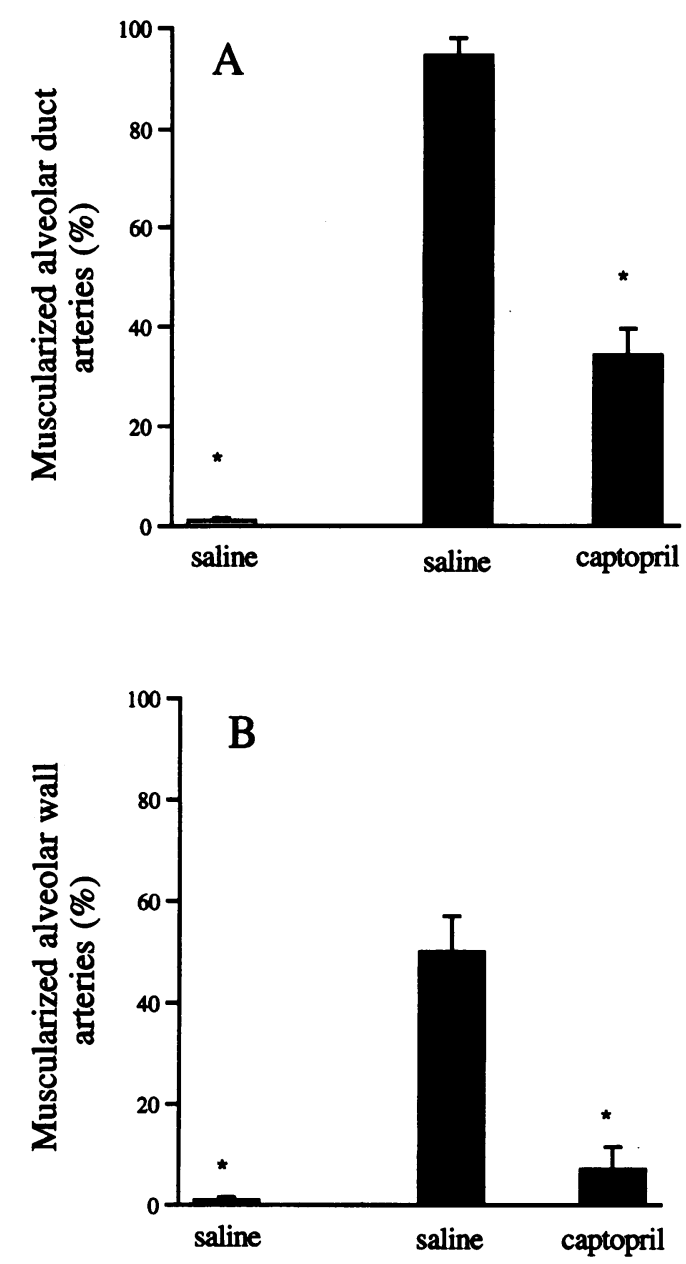

Figure 9. Bar graph showing the percentage of completely muscular arteries, associated with alveolar ducts $(A)$ and alveolar walls $(B)$, in normoxic saline-treated rats (open bars) and chronically hypoxic rats treated with saline or captopril (filled bars). During chronic hypoxia, captopril caused a marked reduction in the distal muscularization of these vessels. ${ }^{*} P<0.05$ compared with hypoxic saline-treated rats.

in ACE antigen with no increase in ACE activity (43). However, these studies were performed on endothelial cells derived from the main pulmonary artery and their findings may not apply to the alveolar capillary endothelial cell. The differential effect of chronic hypoxia which we observed on pulmonary vascular ACE expression (increased expression in small arteries, reduced expression in capillaries) is difficult to explain on the basis of what is presently known about the regulation of endothelial ACE expression. The explanation may be that phenotypically distinct endothelial cells respond differently to the same stimulus. Alternatively, similar cells may be responding to different local stimuli; for example, hypoxia-induced reduction in alveolar capillary ACE expression and a shear stressinduced increase in ACE expression in small constricted pulmonary arteries.

A further important observation in this study was the finding of marked differences in ACE expression along the longitudinal axis of the normal pulmonary vasculature. A similar variation has been described recently in the myocardium $(30,31)$. In normoxic and hypoxic animals there was intense immunostaining of ACE in endothelial cells of small arteries accompanying 
terminal and respiratory bronchioles. These arteries comprise the resistance vessels in the pulmonary circulation, and it makes teleological sense that local AII production should be optimized at the site at which resistance can be most readily controlled. During hypoxia we were unable to demonstrate a further increase in ACE expression in these vessels by immunohistochemistry or in situ hybridization. It is well known that the medial thickness of these vessels increases by smooth muscle cell hypertrophy and hyperplasia during the development of hypoxic pulmonary hypertension (2). Our findings imply that the structural changes in normally muscular vessels are not mediated by increased local ACE expression. However, this does not exclude a role for local AII in the medial thickening of these vessels since it remains possible that increased angiotensin receptor expression, increased local availability of ACE substrate, synergistic interaction with other locally upregulated growth factors, or upregulation of permissive intracellular signaling pathways could also be involved.

In normoxic rats, immunohistochemistry demonstrated that ACE expression was confined to pulmonary vascular endothelium. In the neomuscularized arterioles associated with alveolar ducts and walls in hypoxic rats, the proximity of endothelial and smooth muscle layers (often a single cell layer and incomplete) made it difficult to be certain whether or not nonendothelial cells also expressed ACE. In situ hybridization studies showed increased signal for ACE mRNA in these vessels which often appeared to involve the entire vessel wall rather than being confined to the endothelium, suggesting ACE expression in smooth muscle cells or pericytes. Somatic ACE expression has been demonstrated by immunohistochemistry in many nonendothelial cell types including macrophages, renal tubular epithelium (34), jejunal epithelium (34), and neointimal smooth muscle cells of the balloon injured aorta (10). In addition, ACE activity can be detected in fibroblasts and smooth muscle cells of the normal rat aorta, albeit at a much lower level than in endothelial cells, and aortic smooth muscle cell ACE expression is increased in animals with systemic hypertension (44). Increased ACE activity in proliferating vascular smooth muscle cells might enable these cells to stimulate growth in an autocrine and/or paracrine fashion. Study of microvascular smooth muscle cells and pericytes isolated from the pulmonary vessels will be necessary to determine with certainty whether ACE expression is increased in these cells during hypoxic pulmonary hypertension.

This study demonstrated that whole lung ACE activity has little relation to local vascular ACE expression in the hypoxic lung since the distribution of ACE in the normal lung was nonuniform and the response to hypoxia was specific and localized. Presumably the measured reduction in whole lung ACE activity in the hypoxic lung was due to the marked reduction in alveolar capillary ACE expression demonstrated by immunofluorescence (Fig. 5). It is likely that alveolar capillaries, because of their abundance in the lung, contribute to the majority of ACE activity measured in lung homogenates. The finding of a similar reduction in ACE activity measured using substrates with different affinities for the two active sites on the ACE molecule is more in keeping with a reduction in ACE antigen rather than a differential effect of hypoxia on the $\mathrm{NH}_{2}$ - or $\mathrm{COOH}$-terminal active sites. The reduced expression of ACE by alveolar capillaries during hypoxia could be due to a reduced synthesis of ACE or increased shedding of ACE from the endothelium. This study did not address this question directly, but reduced synthesis of alveolar capillary ACE is suggested by the initial reduction in serum ACE activity up to the fifth day of hypoxia which paralleled the initial fall in lung ACE activity. Circulating ACE is thought to be derived from vascular endothelial sources, and elevated serum ACE is thought to be a marker of endothelial damage such as occurs with reduced lung ACE in oleic acid-induced acute lung injury $(23,33,45)$. The subsequent return of serum ACE activity back to control values by days 8 and 14 of hypoxia in our study is consistent with other reports of unaltered serum ACE after 2 or 3 wk of hypoxia (16, $19)$, though previous authors may have missed the initial fall. The return of serum ACE activity to control values by 8 and $14 \mathrm{~d}$ of hypoxia may be partly due to organ- or tissue-specific increases in ACE activity, such as the increase in renal ACE activity which we observed as early as $3 \mathrm{~d}$ of hypoxia. The site and significance of the increased renal ACE activity were not examined in this study, but both ACE antigen and mRNA have been localized to the proximal convoluted tubule in the normal kidney (34). Clearly increased local generation of AII in the kidney may have important consequences for salt and water balance during chronic hypoxia.

In conclusion, these results demonstrate for the first time that ACE expression is increased locally in the walls of small pulmonary arteries in hypoxic pulmonary hypertension. Moreover, inhibition of ACE caused a marked reduction in the distal muscularization of normally nonmuscular vessels and attenuated pulmonary hypertension. Together, these results suggest a role for ACE in the early pathological remodeling of the hypertensive pulmonary vascular bed. The reduction in whole lung ACE activity measured in chronically hypoxic lungs is due to a reduction in ACE expression in alveolar capillaries, which masks localized increases occurring in small pulmonary arteries.

\section{Acknowledgments}

The authors are indebted to Prof. John T. Reeves (University of Colorado Health Sciences Center, Denver, Colorado) for useful discussion and assistance in preparing this manuscript and to Dr. K. Bernstein for ACE cDNA.

This work was supported by National Institutes of Health grants: SCOR HL-46481, Program Project Grant HL-14985, and an American Lung Association Career Investigator Award to K. R. Stenmark. N. W. Morrell is supported by the British Heart Foundation and in part by a Scadding-Morriston Davies Respiratory Fellowship.

\section{References}

1. Hislop, A., and L. Reid. 1976. New findings in pulmonary arteries of rats with hypoxia-induced pulmonary hypertension. Br. J. Exp. Pathol. 57:542-554.

2. Meyrick, B., and L. Reid. 1979. Hypoxia and incorporation of $\left[{ }^{3} \mathrm{H}\right]$ thymidine by cells of the rat pulmonary arteries and alveolar wall. Am. J. Pathol. 96:51-70.

3. Orton, E. C., S. M. LaRue, B. Ensley, and K. R. Stenmark. 1992. Bromodeoxyuridine labeling and DNA content of pulmonary arterial medial cells from hypoxia-exposed and non-exposed healthy calves. Am. J. Vet. Res. 53:1925-1930.

4. Stenmark, K. R., A. G. Durmowicz, J. D. Roby, R. P. Mecham, and W. C. Parks. 1994. Persistence of the fetal pattern of tropoelastin gene expression in severe neonatal pulmonary hypertension. J. Clin. Invest. 93:1234-1242.

5. Prosser, I. W., K. R. Stenmark, M. Suthar, E. C. Crouch, R. P. Mecham, and W. C. Parks. 1989. Regional heterogeneity of elastin and collagen gene expression in intralobar arteries in response to hypoxic pulmonary hypertension as demonstrated by in situ hybridization. Am. J. Pathol. 135:1073-1088.

6. Durmowicz, A. G., W. C. Parks, D. M. Hyde, R. P. Mecham, and K. R. Stenmark. 1994. Persistence, re-expression, and induction of pulmonary arteria fibronectin, tropoelastin, and type I procollagen mRNA expression in neonatal hypoxic pulmonary hypertension. Am. J. Pathol. 145:1411-1420. 
7. Kifor, I., and V. J. Dzau. 1987. Endothelial renin-angiotensin pathway: evidence for intracellular synthesis and secretion of angiotensins. Circ. Res 60:422-428.

8. Powell, J. S., J.-P. Clozel, R. K. M. Mueller, H. Kuhn, F. Hefti, M. Hosang, and H. R. Baumgartner. 1989. Inhibitors of angiotensin-converting enzyme prevent myointimal thickening after vascular injury. Science (Wash. DC). 245:186245.

9. Shiota, N., M. Miyazaki, and H. Okunishi. 1992. Increase of angiotensin converting enzyme gene expression in the hypertensive aorta. Hypertension (Dallas). 20:168-174.

10. Rakugi, H., D. K. Kim, J. E. Krieger, D. S. Wang, V. J. Dzau, and R. E Pratt. 1994. Induction of angiotensin converting enzyme in the neointima after vascular injury: possible role in restenosis. J. Clin. Invest. 93:339-346.

11. Geisterfer, A. A. T., M. J. Peach, and G. K. Owens. 1988. Angiotensin I induces hypertrophy, not hyperplasia, of cultured rat aortic smooth muscle cells. Circ. Res. 62:749-756.

12. Gibbons, G. H., R. E. Pratt, and V. J. Dzau. 1992. Vascular smooth muscle cell hypertrophy versus hyperplasia. Autocrine transforming growth factor- $\beta_{1}$ expression determines growth response to angiotensin II. J. Clin. Invest. 90:456461.

13. Zakheim, R. M., L. Mattioli, A. Molteni, K. B. Mullis, and J. Bartley. 1975. Prevention of pulmonary vascular changes of chronic alveolar hypoxia by inhibition of angiotensin I-converting enzyme in the rat. Lab. Invest. 33:57-61.

14. Kentera, D., D. Susic, A. Cvetkovic, and G. Djordjevic. 1981. Effects of SQ14.225, an orally active inhibitor of angiotensin-converting enzyme, on hypoxic pulmonary hypertension and right ventricular hypertrophy in rats. Basic Res. Cardiol. 76:344-351.

15. Clozel, J.-P., C. Saunier, D. Hartemann, and W. Fischli. 1991. Effects of cilazapril, a novel angiotensin converting enzyme inhibitor, on the structure of pulmonary arteries of rats exposed to chronic hypoxia. J. Cardiovasc. Pharmacol. 17:36-40.

16. Keane, P. M., J. M. Kay, K. L. Suyama, D. Gauthier, and K. Andrew. 1982. Lung angiotensin converting enzyme activity in rats with pulmonary hypertension. Thorax. 37:198-204.

17. Caldwell, R. W., and C. M. Blatteis. 1983. Effect of chronic hypoxia on angiotensin-induced pulmonary vasoconstriction and converting enzyme activity in the rat. Proc. Soc. Exp. Biol. Med. 172:346-350.

18. Jackson, R. M., A. J. Narkates, and S. Oparil. 1986. Impaired pulmonary conversion of angiotensin I to angiotensin II in rats exposed to chronic hypoxia. J. Appl. Physiol. 60:1121-1127.

19. Oparil, S., A. J. Narkates, R. M. Jackson, and H. S. Ann. 1988. Altered angiotensin converting enzyme in lung and extrapulmonary tissues of hypoxia adapted rats. J. Appl. Physiol. 65:218-227.

20. Kay, J. M., P. M. Keane, K. L. Suyama, and D. Gauthier. 1982. Angiotensin converting enzyme activity and evolution of pulmonary vascular disease in rats with monocrotaline pulmonary hypertension. Thorax. 37:88-96.

21. Coleman, T. G. 1974. Cardiac output by dye-dilution in the conscious rat. J. Appl. Physiol. 37:452-455.

22. Huber, F., I. E. Sodal, and J. V. Weil. 1976. On-line cardiac output by digital computer. J. Appl. Physiol. 40:266-268.

23. Nakiwa, T., R. Matsuoka, H. Takagi, Y. Ichi, T. Arai, and S. Kira. 1982. Responses of serum and lung angiotensin converting enzyme activities in the early phase of pulmonary damage induced by oleic acid in dogs. Am. Rev. Respir Dis. 126:1060-1066.

24. Piquilloud, Y., A. Reinharz, and M. Roth. 1970. Studies on angiotensin converting enzyme with different substrates. Biochim. Biophys. Acta. 206:136142.

25. Friedland, J., and E. Silverstein. 1976. A sensitive fluorometric assay for serum angiotensin-converting enzyme. Am. J. Clin. Pathol. 66:416-424.

26. Danilov, S., E. Jaspardy, T. Churakova, H. Towbin, F. Savoie, L. Wei, and F. Alhenc-Gelas. 1995. Structure-function analysis of angiotensin I-converting enzyme using monoclonal antibodies. J. Biol. Chem. 269:26806-26814.

27. Wei, L., F. Alhenc-Gelas, P. Corvol, and E. Clauser. 1991. The two homologous domains of human angiotensin I-converting enzyme are both catalytically active. J. Biol. Chem. 266:9002-9008.

28. Nakajima, T., T. Yamada, and M. Setoguchi. 1992. Prolonged inhibition of local angiotensin-converting enzyme after single or repeated treatment with quinapril in spontaneously hypertensive rats. J. Cardiovasc. Pharmacol. 19:102107.

29. Danilov, S. M., A. I. Faerman, O. Y. Printseva, A. V. Martynov, I. Y. akharov, and I. N. Trakht. 1987. Immunohistochemical study of angiotensinconverting enzyme in human tissues using monoclonal antibodies. Histochemistry. 87:487-490.

30. Falkenhahn, M., F. Franke, R. M. Bohle, Y.-C. Zhu, H. Stauß, S. Bachmann, S. Danilov, and T. Unger. 1995. Cellular distribution of angiotensin converting enzyme after myocardial infarction. Hypertension (Dallas). 25:219-226

31. Nüsse, T., R. Bohle, T. Unger, S. Danilov, M. Falkenhahn, and F. Franke. 1994. Zelluläre ACE Expression Humanen Myokards bei Normotrophie, Hypertrophie und unter ACE-Inhibition. Z. Kardiol. (Suppl.) 83:100a. (Abstr.)

32. Angerer, L. M., and R. C. Angerer. 1992. In situ hybridization to cellular RNA with radiolabelled RNA probes. In In Situ Hybridization: A Practical Approach. D. G. Wilkinson, editor. Oxford University Press, New York. 15-32.

33. Atochina, E. N., H. H. Hiemisch, V. R. Muzykantov, and S. M. Danilov. 1992. Systemic administration of platelet activating factor in rat reduces specific pulmonary uptake of circulating monoclonal antibody to angiotensin converting enzyme. Lung. 170:349-358.

34. Sibony, M., J.-M. Gasc, F. Soubrier, F. Alhenc-Gelas, and P. Corvol 1993. Gene expression and tissue localization of the two isoforms of angiotensin I converting enzyme. Hypertension (Dallas). 21:827-835.

35. Goraya, T. Y., S. P. Kessler, R. S. Kumar, J. Douglas, and G. C. Sen. 1994. Identification of positive and negative transcriptional regulatory elements of the rabbit angiotensin-converting enzyme gene. Nucleic Acids Res. 22:11941201

36. Meyrick, B. O., and E. A. Perkett. 1989. The sequence of cellular and hemodynamic changes of chronic pulmonary hypertension induced by hypoxia and other stimuli. Am. Rev. Respir. Dis. 140:1486-1489.

37. Rabinovitch, M., W. Gamble, A. S. Nadas, O. S. Miettinen, and L. Reid. 1979. Rat pulmonary circulation after chronic hypoxia: hemodynamic and structural features. Am. J. Physiol. 236:H818-H827.

38. Campbell-Boswell, M., and A. L. Robertson. 1981. Effects of angiotensin II and vasopressin on human smooth muscle cells in vitro. Exp. Mol. Pathol. 35:265-276.

39. Yu, F.-S . S.-L. Lee, and B. L. Fanburg. 1989. Smooth muscle cell conditioned medium elevates angiotensin-converting enzyme of bovine pulmonary artery endothelial cells. Am. J. Respir. Cell Mol. Biol. 1:401-405.

40. Turla, M. B., M. M. Thompson, M. H. Corjay, and G. K. Owens. 1991. Mechanisms of angiotensin II- and arginine vasopressin-induced increases in protein synthesis and content in cultured rat aortic smooth muscle cells. Evidence for selective increases in smooth muscle isoactin expression. Circ. Res. 68:288299.

41. Fishel, R. S., V. Thourani, S. J. Eisenberg, S. Y. Shai, M. A. Corson, E. G. Nabel, K. E. Bernstein, and B. C. Berk. 1995. Fibroblast growth factor stimulates angiotensin converting enzyme expression in vascular smooth muscle cells. $J$. Clin. Invest. 95:377-387.

42. Krulewitz, A. H., and B. L. Fanburg. 1984. The effect of oxygen tension on the in vitro production and release of angiotensin-converting enzyme by bovine pulmonary artery endothelial cells. Am. Rev. Respir. Dis. 130:866-869.

43. King, S. J., F. M. Booyse, P.-H. Lin, M. Traylor, A. J. Narkates, and S. Oparil. 1989. Hypoxia stimulates endothelial cell angiotensin-converting enzyme antigen synthesis. Am. J. Physiol. 256:C1231-C1238.

44. Arnal, J. F., T. Battle, C. Rasetti, M. Challah, O. Costerousse, E. Vicaut, J. B. Michel, and F. Alhenc-Gelas. 1994. ACE in three tunicae of rat aorta: expression in smooth muscle and effect of renovascular hypertension. Am. J. Physiol. 267:H1777-H17784.

45. Muzykantov, V., and S. Danilov. 1991. A new approach to investigation of oxidative injury to the pulmonary endothelium: use of angiotensin converting enzyme as a marker. Biomed. Sci. 2:11-17. 